\title{
Reynolds number-dependent permeability of wastewater sludge flocs
}

\author{
Zeng Yang ${ }^{\mathrm{a}, 1}$, Xiao-Feng Peng ${ }^{\mathrm{a}, 2}$, Duu-Jong Lee ${ }^{\mathrm{b}, 3, *}, \mathrm{Ay} \mathrm{Su}^{\mathrm{c}, 4}$ \\ a Department of Thermal Engineering, Tsinghua University, Beijing 100084, China \\ ${ }^{\mathrm{b}}$ Chemical Engineering Department, National Taiwan University, Taipei 10617, Taiwan \\ ${ }^{\mathrm{c}}$ Department of Mechanical Engineering \& Fuel Cells Research Center, Yuan Ze University, Chungli 320, Taiwan
}

Received 24 July 2006; accepted 25 July 2006

\begin{abstract}
Most theoretical models assume constant permeability of wastewater sludge floc. This work shows that, at creeping flow limit with small intrafloc Reynolds number, the permeability of floc can not only be affected by floc structure, but also by the external flow condition. The threedimensional structure of flocs using the fluorescence in situ hybridization (FISH) and the confocal laser scanning microscope (CLSM) was firstly probed. Then, the volumetric grid models for sludge flocs were constructed. We noted that the floc permeability could keep unchanged, increased, or decreased at increased Reynolds number $(R e)$. Flow redistribution among channels of various sizes contributes to the noted $R e$-dependent permeability of flocs.
\end{abstract}

(C) 2007 Taiwan Institute of Chemical Engineers. Published by Elsevier B.V. All rights reserved.

Keywords: Floc model; CLSM; Permeability; Flow distribution

\section{Introduction}

Sludge flocs are regarded as highly porous fractal-like aggregates composed by many particles (Li and Ganczarczyk, 1989). Numerous structural models of flocs have been proposed to estimate the effects of advective flow on the intrafloc transport processes. Model considering the floc's interior as a uniform porous medium is referred to as the "homogeneous model" (Chu et al., 2004a; Chung et al., 2004; Tsou et al., 2002; Wu et al., 2002; Wu and Lee, 1998, 1999, 2001). The model taking the floc as a porous medium of radially varying porosity (and permeability as well) (Chellam and Wiesner, 1993; Hsu et al., 2005a,b; Hsu and Hsieh, 2003, 2004; Veerapaneni and Wiesner, 1996) is named as "radially varying model". In some relevant works, the floc was regarded as of a self-similar, fractal-like structure (Li and Leung, 2005; Li and Logan, 1997a,b; Li and Yuan, 2002; Li et al., 2003). Solving the equations of motion with pre-described floc structure could

\footnotetext{
* Corresponding author. Tel.: +88622362 5632; fax: +886223623040. E-mail address: djlee@ntu.edu.tw (D.-J. Lee).

1 楊 震
2 彭曉峰
${ }^{3}$ 李篤中
$4{ }^{4}$ 蘇 艾
}

derive the advective flow field. However, up to now no comparisons between the outputs of various floc models were made since there exists no common basis to compare with.

Our group detailed the floc's interior structure by employed the fluorescence in situ hybridization (FISH) technique and confocal laser scanning microscope (CLSM), and subsequently, established the three-dimensional floc model (Chu et al., 2004b, 2005; Chu and Lee, 2004a,b,c). Solving the NaviorStokes equations based on a correlation between floc permeability and interior geometric parameters simulated the flow field in the floc interior. The permeability of sludge flocs could affect the efficiency of various processes, including those in the field of solid-liquid separation processes (Hwang et al., 2005; Skouras et al., 2004; Tan et al., 2004; Tao et al., 2005; Tung et al., 2004).

We demonstrated in this work that the permeability of wastewater sludge floc can be affected not only by floc structure, but also by the external flow condition. The threedimensional model for wastewater flocs was first detailed. Then the advective flow field was numerically simulated, from which the permeability of floc was estimated. The causes corresponding to the noted Reynolds number-dependent permeability of floc was attributable to the change in flow distributions through channels of different sizes could altered at increased Reynolds number. 


\section{Experimental}

\subsection{The samples}

Waste activated sludge was taken from the Min-Sheng Municipal Wastewater Treatment Plant in Taipei, which was gravitationally settled to a solid content of around $15000 \mathrm{mg} \mathrm{L}^{-1}$, and was the testing sample for the present work. The chemical oxygen demand (COD) for the sludge was $24400 \mathrm{mg} \mathrm{L}^{-1}$, obtained from direct reading spectrometer (DR/2000, HACH, USA). Dry solids density of sludge was measured by an Accupyc Pycnometer 1330 (Micromeritics) as $1450 \mathrm{~kg} \mathrm{~m}^{-3}$. The original flocs A-C were sampled from the original sludge.

Some sludge samples were flocculated by the cationic flocculant, a polyacrylamide of an average molecular weight of $10^{7}$ daltons (Da) and a charge density of $20 \%$. The polymer solution was gradually poured into the mixing vessel to a dose of $40 \mathrm{mg} \mathrm{L}^{-1}$ containing fresh sludge samples with $200 \mathrm{rpm}$ of stirring for $5 \mathrm{~min}$ (rapid mix) followed by $50 \mathrm{rpm}$ of another 20 min (slow mix). The "flocculated flocs" A-C were sampled from the flocculated sludge thus prepared.

Some sludge samples were frozen at $-17{ }^{\circ} \mathrm{C}$ for $24 \mathrm{~h}$ and then thawed at room temperature for $22 \mathrm{~h}$. The "freeze/thawed flocs" A-C were sampled from the treated sludge.

\subsection{FISH and CLSM}

Sludge flocs for confocal laser scanning microscope (CLSM) analysis were first fixed with $3 \%$ paraformadehyde in phosphate-buffered saline (PBS). Then the fixed sample was embedded in low-melting-point agar (with melting point of $75^{\circ} \mathrm{C}$ and gelling point of $38^{\circ} \mathrm{C}$ ) for the fluorescence in situ hybridization (FISH). In this study, we used the probe, EUB338 (labeled by rhodamine) and ARCH915 (labeled by tetrachlorofluorescein), for detection of members of domain bacteria with high cellular ribosome content and those that cannot be detected by EUB338. The stained samples were washed three times to remove extra probes by hybridization buffer solution. The present work employed the CLSM (OLYMPUS BX50) equipped with an image processor (OLYMPUS FV5 PSU) and an argon laser source to stimulate the fluorescence. The sludge floc was imaged with a $10 \times$ objective with the software FLUOVIEW Version 3.0. The microscope scanned the samples at fixed depth and digitized the image obtained.

\subsection{Image processing}

More than 150 CLSM images were sampled for a typical floc, and the image-thresholding algorithm - Otsu's method (Otsu, 1979) - determined the thresholding values of sliced images. Three-dimensional image for the floc was reconstructed using the bileveled CLSM images. Then, the software, Amira 3.0 (TGS Inc., U.S.A.), was used to reconstruct the thresholded sliced images as isosurfaces (polygonal surface models and volumetric grids). The reconstruction procedures follow those in Chu and Lee (2004b) with refinements. The mesh model for the original floc A was shown in Fig. 1.

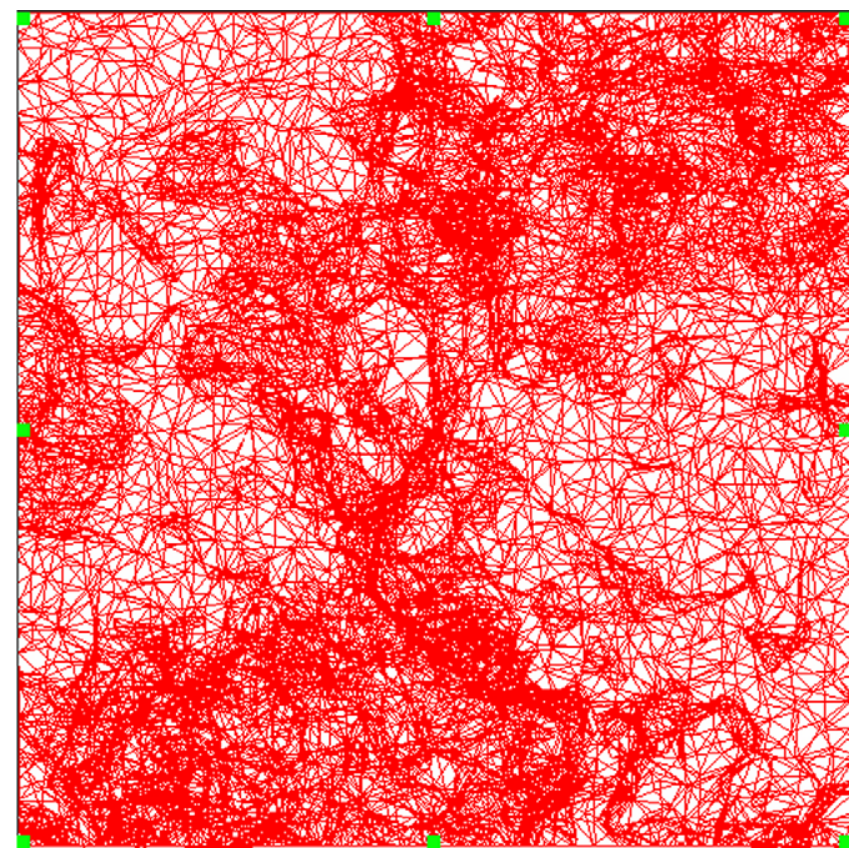

Fig. 1. Tetrahedral volumetric grids of pore of original floc A.

\subsection{Equations and solution}

One of the six faces on the cuboid model (like that in Fig. 1) was defined as the inlet, and the opposite face was defined as the outlet. Thus, every cuboid model has three cases for calculations-along $x, y$ and $z$ directions. The model floc was placed at

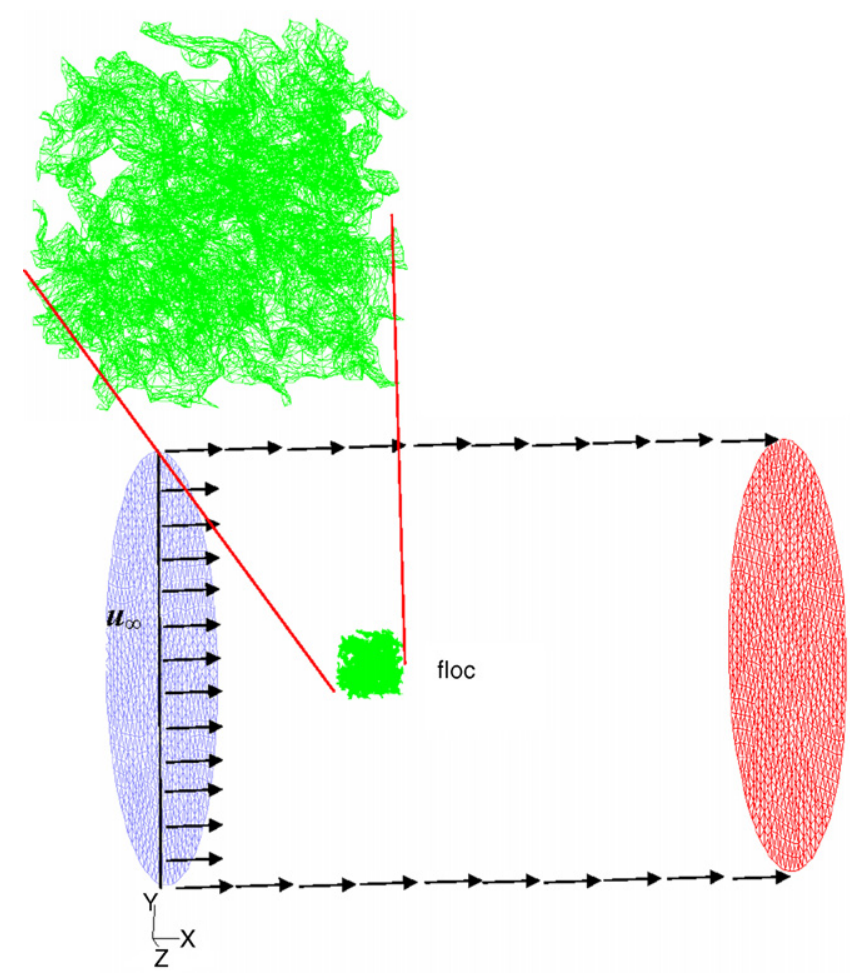

Fig. 2. The computational domain adopted in this study: the ratios of cube length to the diameter and length of outside cylinder are 1:8 and 1:12, respectively. 
the center of a fluid field of width and length 8 and 12 times to the floc model (Fig. 2). A uniform fluid flow $u_{\infty}$ was imposed at the entry plane and at the side-walls. This flow system is equivalent to that with a model floc moving at a velocity $u_{\infty}$ though an infinite, quiescent water. The direction of $u_{\infty}$ is set as parallel to the $x, y$ or $z$-axis, respectively, for exploring the effective permeability along each principal direction. The tetrahedral grids generated using Amira 3.0 were first preprocessed using geometry modeling mesh generation software, GAMBIT 2.0

(a)

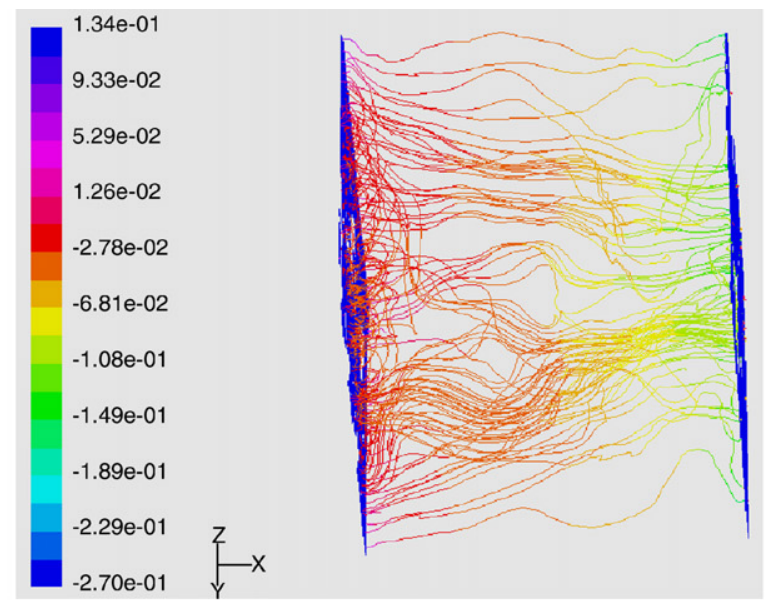

(b)

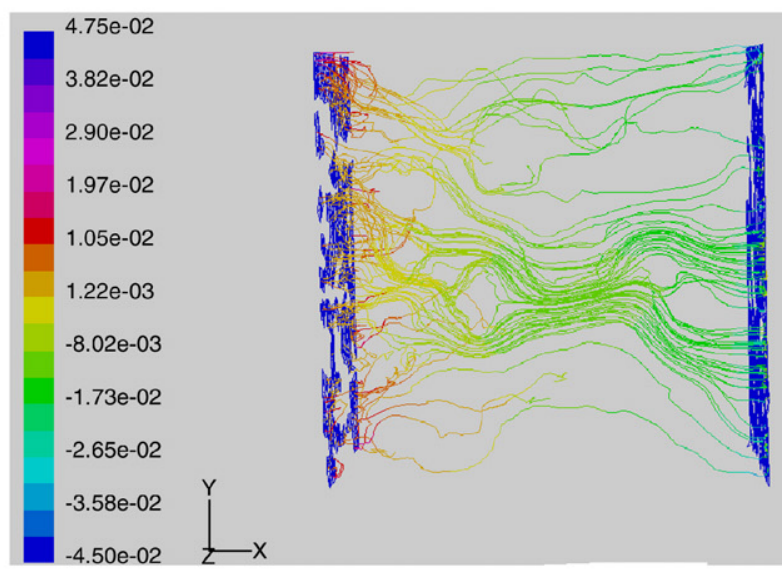

(c)

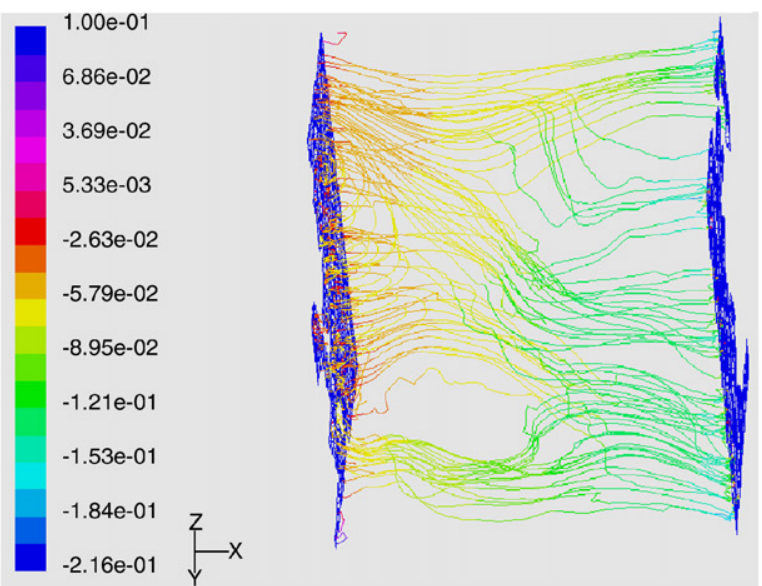

Fig. 3. Path lines in the floc cube subject to $x$-directional flow, colored by static pressure (Pa, gauge): (a) original floc $\mathrm{A}$, (b) flocculated floc $\mathrm{A}$ and (c) freeze/ thawed floc.
(Fluent Inc., USA), to define the inlet, outlet and walls, to solve the governing equations and boundary conditions for intrafloc velocity, $\vec{u}$. The models were then solved using software, FLUENT 6.0 (Fluent Inc., USA). The pressure-velocity coupling algorithm was SIMPLEC (semi-implicit method for
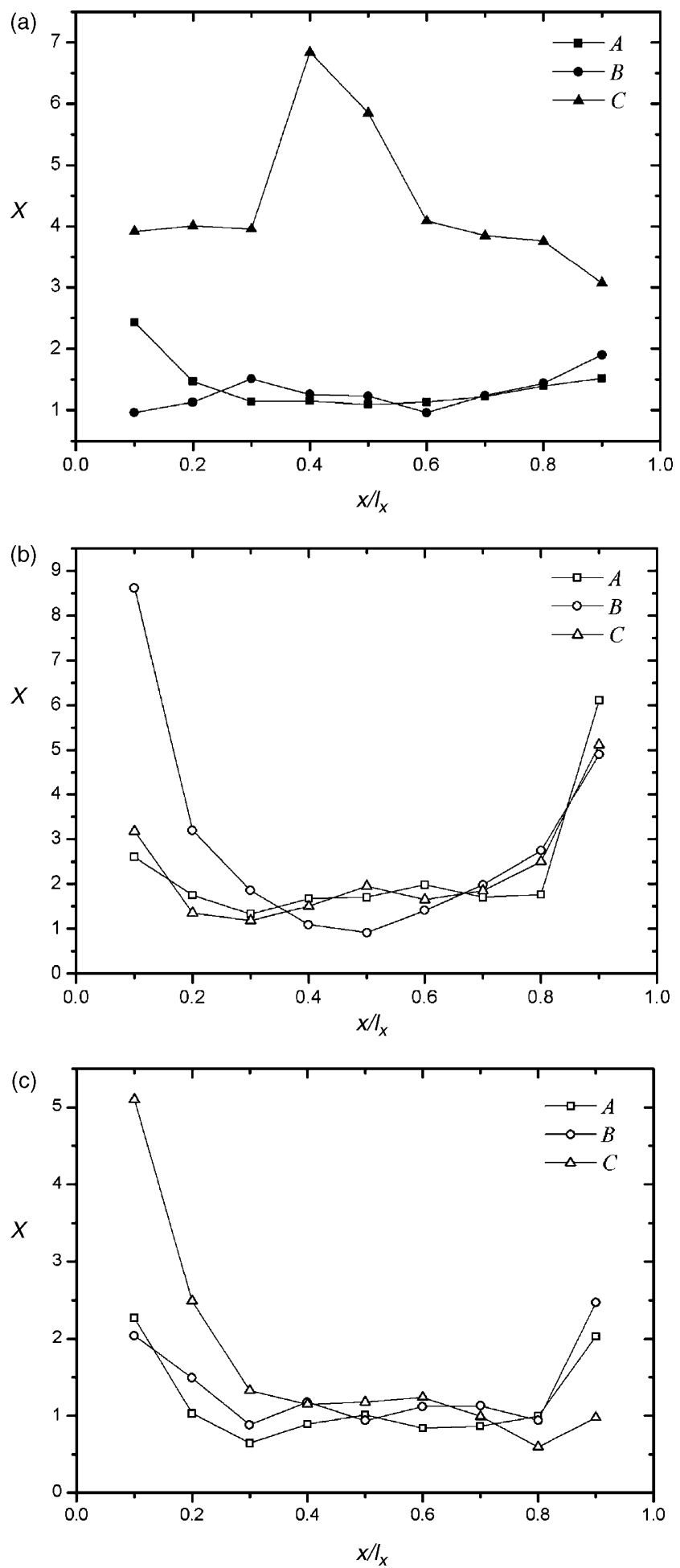

Fig. 4. Flowrate distribution factor, $\chi$, in the floc region at different positions along the $x$-directional flow, the position coordinate is normalized by the cubic length in the flow direction, $l_{x}$ : (a) original flocs, (b) flocculated flocs and (c) freeze and thawed flocs. 
pressure-linked equations-consistent). The calculation was performed at a maximum relative error of $0.1 \%$. The Reynolds number of the floc is defined as follows:

$\operatorname{Re}=\frac{u_{\infty} l_{\mathrm{m}}}{v}$

where $l_{\mathrm{m}}$ is the geometrical mean of the size of the model floc, and $v$ is the kinematic viscosity of fluid. Notably, the Reynolds number in Eq. (1) is based on the external flow velocity.

\section{Results and discussion}

\subsection{Intrafloc flow}

Fig. 3 plots the path lines along $x$-axis for original floc A, flocculated floc $\mathrm{A}$, and freeze/thawed floc $\mathrm{A}$. The path lines were colored according to the static pressure (gauge), measured in Pascal. Very tortuous path lines were noticed, yielded by the rather complicated floc interior structure for water to flow through. The intrafloc velocity will increase by a factor of around 150 when the external Reynolds number increases from 0.1 to 100 . If based on the channel diameter and channel velocity, the maximum Reynolds number inside the floc would be less than 1 at $R e=100$, indicating that the intrafloc flow is a laminar flow.

A flow distribution factor quantifies the non-uniformity of intrafloc flow over the cross-section $A_{\mathrm{sec}}$ of floc as follows:

$\chi=\frac{\int_{A_{\mathrm{sec}}}\left(|\vec{u}|-u_{\mathrm{m}}\right)^{2} \mathrm{~d} A_{\mathrm{sec}}}{u_{\mathrm{m}}^{2} A_{\mathrm{sec}}}$

where $u_{\mathrm{m}}$ is the mean velocity over the cross-section. A uniform flow gives $\chi=0$ while the laminar flow in a straight circular pipe yields $\chi=0.33$.

With fluid moving along $x$-axis, all $\chi$ 's for the nine investigated flocs at various axial positions $\left(x / l_{\mathrm{m}}\right)$ are greater than 0.33 (Fig. 4). In some case this value can reach 8.5, representing a highly heterogeneous intrafloc flow field.

\subsection{Re-dependent floc permeability}

The area-weighted average pressure of the cross sections perpendicular to the flow direction was used to determine the average pressure drop in the floc, and the permeability, based on Darcy's law, was estimated using the following equation:

$k=\frac{u_{\mathrm{m}} \mu L}{\Delta P}$

where $\mu$ and $\Delta P$ are the liquid viscosity and pressure drop, respectively. Some permeability data are shown in Fig. 5.

The floc permeability could increase (such as original A floc along $z$-axis, and original $\mathrm{C}$ floc along $x$-axis), decrease (such as flocculated B floc along $z$-axis, and freeze/thawed B floc along $x$ axis), or keep unchanged (such as original A floc along $x$-axis, and flocculated $\mathrm{C}$ floc along $x$-axis) at increasing $R e$. (Fig. 5). The Reynolds number for intrafloc flow should be less than unity over $R e=0.1-100$. Hence, in viscous controlled regime the pressure drop by fluid flow would be proportional to Re. Based on the definition of Eq. (3), the permeability should be a constant regardless of external $R e(0.1-100)$. The noted $R e$-dependent permeability in Fig. 5 should be attributable to other causes.

\subsection{Intrafloc flow re-distribution}

Structure in a floc is complicated with many channels of various sizes intersecting with each other. The majority of intrafloc flow would pass through large rather than small channels at fixed $R e$. We hence only consider the several largest channels in the following discussion. The largest one is termed "big channel"; while the second or third largest channels were the "small channels".

When the external flow velocity increases, the intrafloc fluid flow can redistribute among large and small channels, hence

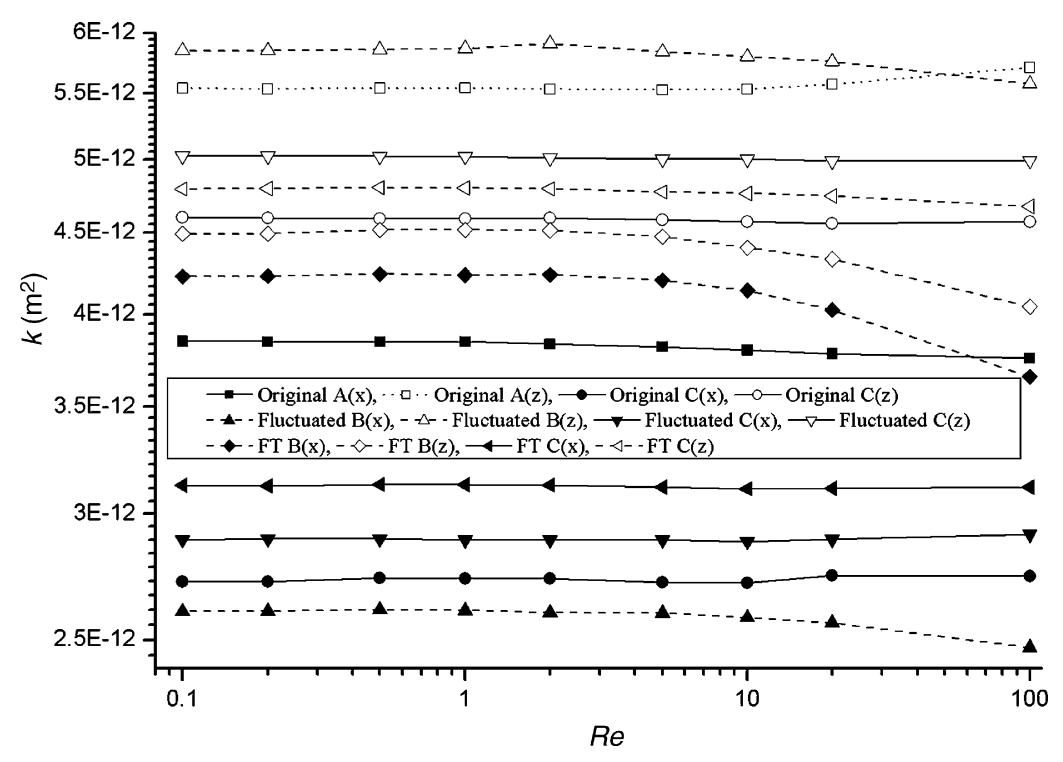

Fig. 5. Permeability versus $R e$ : the flow directions are denoted in the parentheses. 
yielding a $R e$-dependent permeability. Consider two straight, circular, and smooth channels of diameter 50 and $5 \mu \mathrm{m}$ and of length $200 \mu \mathrm{m}$ subjected to a pressure drop of $1 \mathrm{~Pa}$. Then the intra-channel flow rates will be $3.14 \times 10^{-12}$ and $3.14 \times$ $10^{-16} \mathrm{~m}^{3} / \mathrm{s}$, respectively. At a pressure drop of $1 \mathrm{kPa}$, on the other hand, the corresponding flow rates are $3.14 \times 10^{-9}$ and $3.14 \times 10^{-13} \mathrm{~m}^{3} / \mathrm{s}$, respectively. Restated, since the flow regime is laminar flow and the inertial force is not effective to flow in straight channel at $R e<2100$, the intra-channel flow rate is proportional to $D^{4}$ (Hagen-Poiseuille law) and to $\Delta P$, giving a constant permeability based on Eq. (3). Restated, the model by Wu et al. (2003) assuming the interior pores of a floc as many parallel, but independent pores of different sizes will yield a constant permeability over the floc regardless of $R e$ if only intrafloc Reynolds number $<2100$.

Fig. 6 shows the velocity vectors at the central session of flocs exhibiting different permeability-Re dependency. The advective flow exhibits a highly non-uniform velocity distribution over the cross-section. The middle planes perpendicular to the flow directions of the three flocs in Fig. 6 were divided into $10 \times 10$ sub-regions of equal area, numbered by $0-99$, respectively. Then the flow rates flowing through each sub-regions at $R e=0.1$ or 100 were shown in Fig. 7(a)-(c). (a)

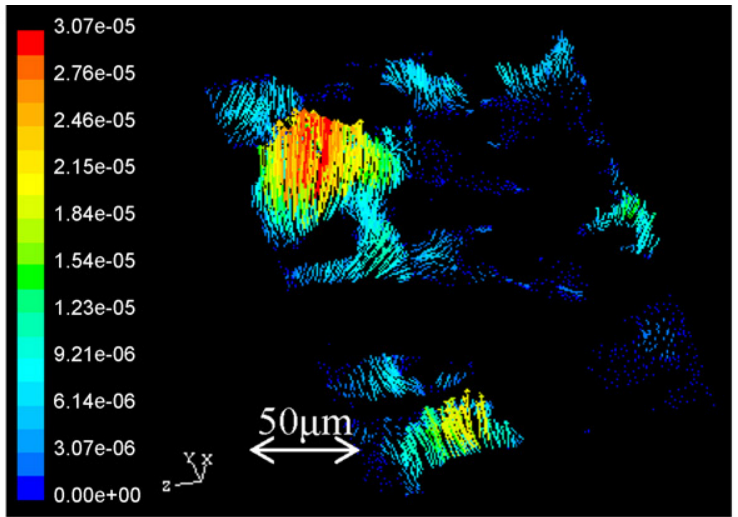

$\operatorname{Re}=0.1$

(b)

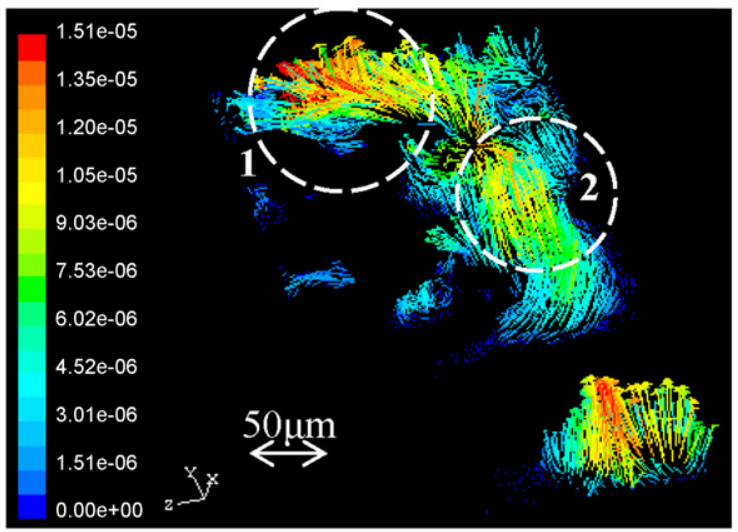

$R e=0.1$

(c)

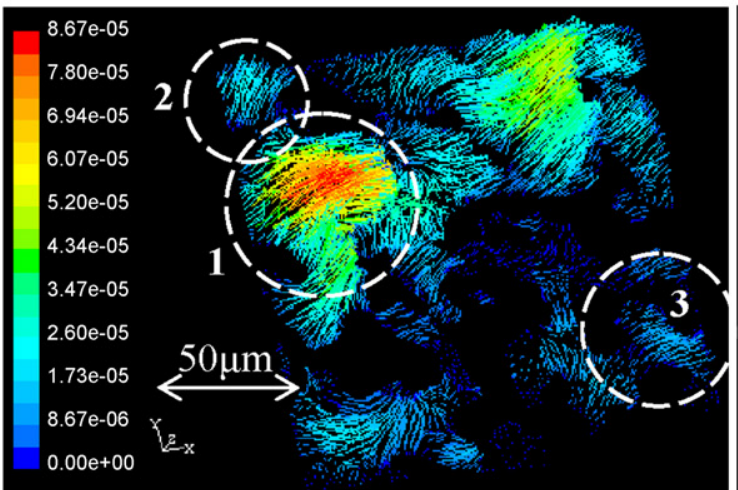

$R e=0.1$

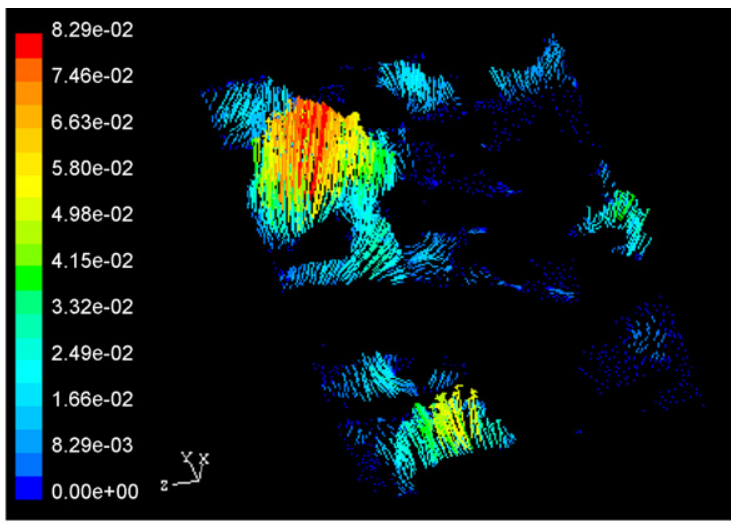

$\operatorname{Re}=100$

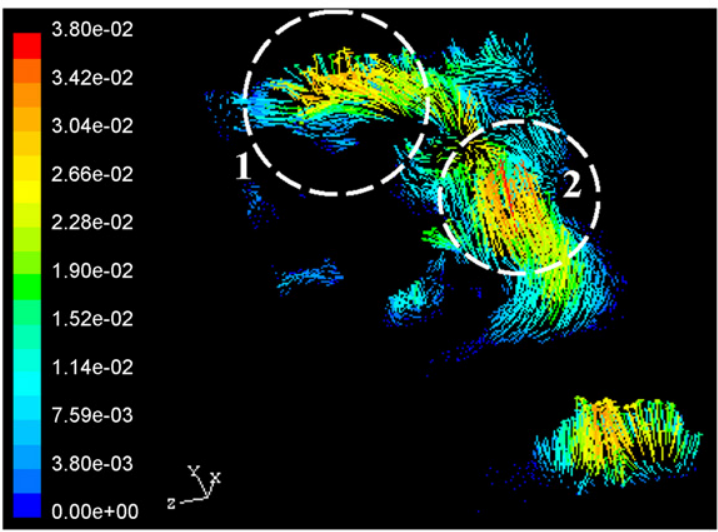

$\operatorname{Re}=100$

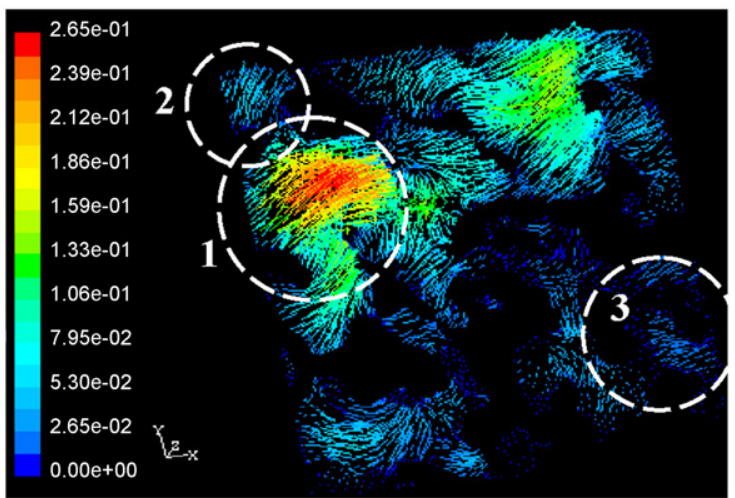

$\operatorname{Re}=100$

Fig. 6. Velocity vectors on the middle plane of flocs: (a) flocculated floc $\mathrm{C}$ along $x$-axis, (b) flocculated floc B along $x$-axis and (c) original floc A along $z$-axis. 

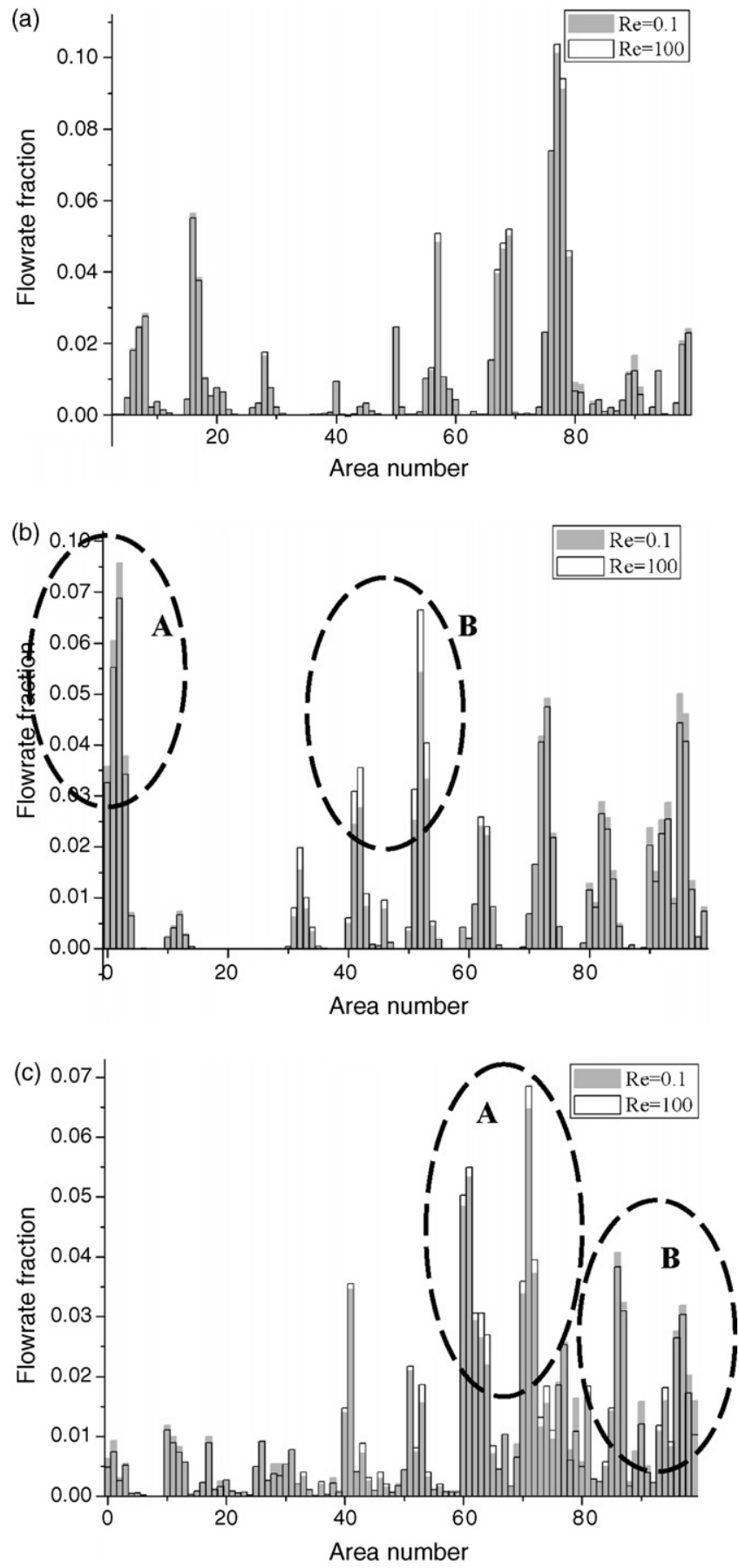

Fig. 7. Distributions of flowrate on the middle plane of flocs: (a) flocculated floc C along $x$-axis, (b) flocculated floc B along $x$-axis and (c) original floc A along $z$ axis.

As Figs. 6(a) and 7(a) shows, although with different magnitudes, the flow velocity distribution for flocculated $\mathrm{C}$ along $x$-axis keeps almost unchanged at $R e=0.1$ or 100 . This observation correlates with the nearly constant permeability versus $R e$ relationship for that floc (Fig. 5). The fraction of fluid flowing through big channel (marked as " 1 ") of flocculated floc B along $x$-axis has decreased when $R e$ was increased from 0.1 to 100 (Fig. 6(b)). Correspondingly, a larger fraction of fluid has flown through a neighboring pore of smaller size (marked as " 2 "). This observation correlates with the decreasing permeability versus $R e$ relationship for that floc (Fig. 5). A more complete view on the change in distribution is available in Fig. 7(b). Meanwhile, the fraction of fluid flowing through big pore (marked as " 1 ") of Original C along $z$-axis has increased when $R e$ was increased from 0.1 to 100 (Fig. 6(c)). Correspondingly, a higher fraction of fluid has flown through neighboring pores of smaller size (marked as " 2 " and " 3 "). Similar conclusion can be drawn from Fig. 7(c).

Restated, if the flow distribution over the floc cross-section has kept unchanged, the permeability is independent of external $R e$. On the other hand, if more fluid would flow through large channels at increased $R e$, the corresponding average permeability would be increased. Similarly, when more fluid was forced through small channels at increased $R e$, the corresponding average permeability would decrease with increasing $R e$.

Chu and Lee (2004c) noted that the pore tortuosity affects significantly the intrafloc flow field, hence influences the floc permeability at fixed $R e$. Moreover, the connectivity of neighboring pores can affect the distribution of advective flow through the floc. Consider two neighboring channels of different sizes and different tortuosities with some connected channels. If the big channels were more tortuous than the small pore, then increasing $R e$ would induce more significant inertia drag force, and then forcing a higher fraction of advective flow through small, neighboring pore. This occurrence could produce a decreased permeability. Similarly, if the big channels were less tortuous than the small channels, the flow distribution would change accordingly, and leading to an increased permeability at increased $R e$. If the big and small channels are of alike tortuosity, the permeability of floc would be independent of $R e$.

\section{Conclusion}

The three-dimensional structure of flocs using the fluorescence in situ hybridization (FISH) and the confocal laser scanning microscope (CLSM) were probed. Then the CLSM images for original, cationically flocculated, and freeze/thawed flocs were sampled, bileveled, and used to construct the polygonal surface models and volumetric grids. Structure in a floc is complicated with many channels of various sizes intersecting with each other. If the distribution of intrafloc flow would keep unchanged at increased Reynolds number $(R e)$, probably since the large and small channels in the floc have similar tortuosity, the permeability is a constant. If more fluid would be forced to flow through small channel than large channel at increased $R e$, probably owing to a lower tortuosity of the former than the latter channel, the permeability would decrease with $R e$. Similarly, if more fluid would be forced to flow through large channel than small channel at increased $R e$, probably owing to a lower tortuosity of the large than the small channel, the permeability would increase with $R e$.

\section{References}

Chellam, S. and M. R. Wiesner, "Fluid-Mechanics and Fractal Aggregates," Water Res., 27, 1943 (1993). 
Chu, C. P. and D. J. Lee, "Multiscale Structure of Biological Flocs," Chem. Eng. Sci., 59, 1875 (2004a).

Chu, C. P. and D. J. Lee, “Advective Flow in a Sludge Floc," J. Colloid Interf. Sci., 277, 387 (2004b).

Chu, C. P. and D. J. Lee, "Effects of Pore Geometry on Intrafloc Flow," J. Chin. Inst. Chem. Engrs., 35, 659 (2004c).

Chu, C. P., D. J. Lee, and X. Y. You, “Normal Stress of Wastewater Sludge,” J. Chin. Inst. Chem. Engrs., 35, 581 (2004a).

Chu, C. P., D. J. Lee, and X. F. Peng, "Structure of Conditioned Sludge Flocs," Water Res., 38, 2125 (2004b).

Chu, C. P., D. J. Lee, and J. H. Tay, "Floc Model and Intrafloc Flow," Chem. Eng. Sci., 60, 565 (2005).

Chung, H. Y., C. P. Chu, and D. J. Lee, "Drag Force on Sludge Flocs under Crossflow," J. Chin. Inst. Chem. Engrs., 35, 225 (2004).

Hsu, J. P. and Y. H. Hsieh, "Boundary Effect on the Drag Force on a Nonhomogeneous Floc,” J. Colloid Interf. Sci., 264, 517 (2003).

Hsu, J. P. and Y. H. Hsieh, "Moving of a Nonhomogeneous, Porous Floc Normal to a Rigid Plate," J. Colloid Interf. Sci., 275, 309 (2004).

Hsu, J. P., M. C. Li, and A. C. Chang, "Drag of a Dispersion of Nonhomogeneously Structured Flocs in a Flow Field," J. Colloid Interf. Sci., 284, 332 (2005a).

Hsu, J. P., S. J. Yeh, and D. J. Lee, "Drag on Two Coaxial, Nonuniformly Structured Flocs in a Uniform Flow Field," J. Colloid Interf. Sci., 292, 290 (2005b).

Hwang, K. J., Y. C. Shie, and Y. S. Lin, "Cake Formation and Flux Decline in Centrifugal Filter Basket,” J. Chin. Inst. Chem. Engrs., 36, 517 (2005).

Li, D. H. and J. J. Ganczarczyk, "Fractal Geometry of Particle Aggregates Generated in Water and Wastewater Treatment Processes," Environ. Sci. Technol., 23, 1385 (1989).

Li, X. Y. and B. E. Logan, "Collision Frequencies of Fractal Aggregates with Small Particles by Differential Sedimentation,” Environ. Sci. Technol., 31, 1229 (1997a).

Li, X. Y. and B. E. Logan, "Collision Frequencies Between Fractal Aggregates and Small Particles by Turbulently Sheared Fluid," Environ. Sci. Technol., 31, 1237 (1997b)

Li, X. Y. and Y. A. Yuan, "Settling Velocities and Permeabilities of Microbial Aggregates," Water Res., 36, 3110 (2002).
Li, X. Y., Y. A. Yuan, and H. W. Wang, "Hydrodynamics of Biological Aggregates of Different Sludge Ages: An Insight into the Mass Transfer Mechanisms of Bioaggregates," Environ. Sci. Technol., 37, 292 (2003).

Li, X. Y. and R. P. C. Leung, "Determination of the Fractal Dimension of Microbial Flocs from the Change in Their Size Distribution after Breakage," Environ. Sci. Technol., 39, 2731 (2005).

Otsu, N., "A Thresholding Selection Method from Gray-Level Histogram," IEEE Trans. System, Man, Cyber, 9, 62 (1979).

Skouras, E. D., V. N. Burganos, C. A. Paraskeva, and A. C. Payatakes, "Simulation of Downflow and Upflow Depth Filtration of Non-Brownian Particles under Constant Flowrate or Constant Pressure Drop Conditions," J. Chin. Inst. Chem. Engrs., 35, 87 (2004).

Tan, R. B. H., C. H. Wang, and K. C. Loh, "Solid-Liquid Separation Research at the National University of Singapore," J. Chin. Inst. Chem. Engrs., 35, 1 (2004).

Tao, T., X. F. Peng, and D. J. Lee, "Crack Dynamics of Thermally Dried Sludge Cake," J. Chin. Inst. Chem. Engrs., 36, 511 (2005).

Tsou, G. W., R. M. Wu, P. S. Yen, D. J. Lee, and X. F. Peng, "Advective Flow and Floc Permeability," J. Colloid Interf. Sci., 250, 400 (2002).

Tung, K. L., Y. L. Lin, T. C. Shih, and W. M. Lu, "Fluid Flow through Compressible Gel Particles Bed: A Steady-State Condition," J. Chin. Inst. Chem. Engrs., 35, 101 (2004).

Veerapaneni, S. and M. R. Wiesner, "Hydrodynamics of Fractal Aggregates with Radially Varying Permeability," J. Colloid Interf. Sci., 177, 45 (1996).

Wu, R. M. and D. J. Lee, "Hydrodynamic Drag Force Exerted on a Moving Floc and Its Implications to Free Settling Test," Water Res., 32, 860 (1998).

Wu, R. M. and D. J. Lee, "Highly Porous Sphere Moving through Centerline of Circular Tube Filled with Newtonian Fluid," Chem. Eng. Sci., 54, 5717 (1999).

Wu, R. M. and D. J. Lee, "Hydrodynamic Drag on Non-Spherical Floc and Free-Settling Test," Water Res., 35, 3226 (2001).

Wu, R. M., D. J. Lee, and P. J. He, "Estimation of Floc Permeability and Porosity," J. Chin. Inst. Chem. Engrs., 34, 275 (2003).

Wu, R. M., G. W. Tsou, P. S. Yen, D. J. Lee, and X. F. Peng, "Tracking Advective Flow through Floc Interior," J. Chem. Eng. Jpn., 35, 540 (2002).

\title{
污泥膠羽隨雷諾數變化之透過率
}

\author{
楊 震 彭曉峰 \\ 中國北京清華大學熱能系 \\ 李篤中 \\ 國立台灣大學化學工程學系 \\ 蘇 艾 \\ 元智大學機械工程學系暨燃料電池中心
}

摘 要

文獻中膠羽模型多假設膠羽內部具有相同之透過率。本研究則發現在低雷諾數之緩流極限下, 膠羽內部透過率不僅 受內部結構影響, 同時亦為外部流通狀況之函數。膠羽內部三維結構模型以螢光雜交及共軛焦雷射掃瞄顯微鏡技術建立, 依此發現膠羽內部透過率隨外部雷諾數增加而上升、下降、或保持不變。其原因在於膠羽內部流場會隨外部流場重新配 置。 